\title{
Teacher Perspective on Internet Censorship in Turkey
}

\author{
Sayim Aktay \\ Faculty of Education, Mugla Sitki Kocman University, Turkey
}

Copyright(C2018 by authors, all rights reserved. Authors agree that this article remains permanently open access under the terms of the Creative Commons Attribution License 4.0 International License

\begin{abstract}
There has been a rapid increase both in the number of users and the number of websites providing data since the invention of Internet; it has become the richest and most used source of information. However, several countries, including Turkey, resort to censorship owing to the fact that anybody can publish on the Internet with sometimes undesirable content. The main purpose of this study is to reveal how primary and secondary school teachers approach Internet censorship in Turkey. The study was conducted with a voluntary group of 2015 primary (855) and secondary (1160) school teachers who had social media accounts in Turkey during the 2013 - 2014 academic year in the spring semester. In the study, a survey was used. The study reveals that $59.4 \%$ of teachers think that it is necessary to resort censor the Internet from undesirable content like sexuality and gambling. On the other hand, the vast majority of the teachers $(86.6 \%)$ do not approve the blocking of websites as they can be used as an educational tool. Moreover, $60.5 \%$ believe that blocking of certain Internet websites will not negatively affect education.
\end{abstract}

Keywords Internet Censorship, Primary Education, Secondary Education

\section{Introduction}

\subsection{The Internet and Internet Censorship}

The Internet, which was created in 1969 by the United States Ministry of Defense with the intent of developing a system able to operate even in case of emergencies like nuclear strikes, has turned into a vast information network interconnecting countries and computers that enterprises and individuals use for data exchange [24]. The Internet has been improved and renewed in terms of both infrastructure and features over the years, and has become more accessible to an ever increasing number of people thanks to increasing bandwidth and reduced price [56].

The websites broadcasting and providing information on the Internet have continued to increase in number with the improvement of the Internet. Some 19.7 thousand domain names existed on the Internet in 1995. As of October 2016, recent estimations by Netcraft have revealed that there are 1.82 billion registered domain names $[42,43]$. The Internet also has an increasing number of user groups. Based on data from Internetworldstats.com, in 1995 just 16 million people - or $0.4 \%$ of world's population - had Internet access. As of September 2017 that number has exponentially increased to 3.88 billion people - accounting for $51.7 \%$ of the world's population $[27,28]$. Examining Internet statistics, it can be observed that Internet use is on the rise both in terms of numbers and active domain names.

Internet censorship has posed social problems in various countries due in part to there being such a large user of numbers worldwide. Thus, several issues have arisen pertaining authorization and authority in terms of who controls the Internet and who decides which content is allowed [10]. When looking at how censorship is applied, one can observe the use of partial censorship such the blocking of social media content (i.e. a user's Twitter feed) alongside the complete blocking of websites [58]. When looking at the world on whole, many countries such as China [60, 6], Pakistan [40, 39], Iran [7], and Syria [13] apply Internet censorship. When examining reports produced by OpenNet Initiative, the number of countries that censor the Internet can be said to be over 80 [44].

Internet censorship is sometimes used by countries as a means of preventing the general public from learning about their leaders' errors [1]. In addition, while the censorship may sometimes be perceived in terms of suppressing ideas of certain individuals, groups and government officers imposing the phenomena considered to be true and lawful by the state may also be thought of as a necessity in order to protect children and moral values and improve society [1, 25]. As an example, in some U.S. states content filtering exists on public computers used in Internet cafes, schools, and libraries [61]. In the context of Internet censorship, methods such as Boarder Gateway Protocol tampering, DNS tampering, and Packet filtering can be used to restrict certain content $[18,36]$. The use of various censorship methods can be seen today in countries such as Pakistan, China, Quatar and the United Arab Emirates [38, 45]. In 
addition to state institutions, certain companies also censor their Internet. In one Italian study done involving $3 \mathrm{G}$ and $4 \mathrm{G}$ networks, a range of censorship of between $32.5 \%$ and $99.5 \%$ was found [4].

Today, when certain states and institutions apply Internet censorship, people either change how they act online or they try one of any number of ways to bypass the censorship. In one study done, it was observed that people who were confronted with censored Internet content were either able to shift towards an alternative source, search for other related content or, upon giving up, shift to doing another activity else entirely [31]. In study done involving 51 Pakistani university students, the students were observed using VPS, web proxy, Tor, and various other means to bypass the censorship [2]. In yet another study done involving 770 individuals in Pakistan, some $57 \%$ of people were observed using VPN programs to get around the censorship [31]. It's been demonstrated that those who manage to bypass the censorship first express the most interest in blocked social media content [29]. However, according to a study done by Callanan \& Jerman-Blazic [12] involving 664 participants from 10 Asian and African countries, $34 \%$ of users confronting blocked content experienced security problems.

\subsection{Internet Censorship Studies}

In some countries, people's reaction towards Internet censorship in terms of opinion differs towards the country [19]. For example, upon asking Americans' opinions on Internet censorship, some have stated that online content must be censored in order to achieve children safety, a civilized society, national security, and creativity. On the other hand, others have suggested that people must be able to share their ideas in order to express themselves online even if their ideas are controversial [62]. Similarly, in a 2005 study put forth by Hostway involving 2500 people, it was determined that bloggers need to be prohibited from sharing people's addresses and personal information online [32].

In a 1994 - 1996 study of more than 15,000 participants [11], $36 \%$ of those participants stated that Internet censorship is the most prominent issue concerning the Internet. In a 1998 American study of 4247 people [17], $47 \%$ of participants indicated that certain types of information must not be allowed on the Internet, while $44 \%$ objected to Internet censorship. In a 2007 Australian study of 17.881 people [59], $74 \%$ of the participants objected to government-imposed content filtering systems. In a 2001-person Chinese study [34], more than $80 \%$ of the participants claimed that certain content like pornography and violence must be censored. In a $2010 \mathrm{BBC}$ study of 26 countries of 27,973 people, [9], 53\% of overall participants, $83 \%$ of South Korean participants, $77 \%$ of Nigerian participants, and $72 \%$ of Mexican participants demanded that purported that the Internet must not restricted by any governmental body. In one study put together involving a total of 7,357 people from Hong Kong, India, Indonesia, Japan, South Korea, Malaysia, Pakistan, Singapore, Taiwan, Thailand, and Vietnam, it's believed that some $78 \%$ of users wanted freedom of expression, and approximately $90 \%$ of users felt that freedom of expression is a basic human right. However, over two out of every three users expressed that Internet censorship, too, is necessary. A large proportion of users were furthermore of the opinion that censorship needs to be applied in situations such as pornography, gambling, and violation of rights [55].

\subsection{The Internet from the Perspective of Education}

The Internet is a substantial information-sharing tool that enables people to communicate with each other via such means as e-mail and instant messaging. Add to that, all types of transactions from banking to shopping can be done via it [26]. Today, the Internet also provides educational benefits like access to educational information, online expertise, lesson plans, and teacher forums [8]. The Internet's becoming one of today's most important educational tools means that integrating it into teaching has also reached become of importance. Libraries, educators, and institutions thus are trying hooking schools up to the Internet, whereby school programs and textbooks too are even becoming digitized [52].

The Internet today has become a key well of information for especially families, students, and teachers [51]. It also has plays a positive role in students', teachers' administrators', and families' lives [5]; thus entailing that a great amount of money is being invested worldwide by families and schools into Internet-based technology such as computers [57]. It appears that the Internet. It appears that for students, the Internet is believed to play an integral role as part of a modern education [50].

When it comes to researching information, the Internet has changed how young students gain access to information by means of offering a number of advantages. One study done involving young pupils had revealed some $97 \%$ of students had obtained information via the Internet rather than using the library [41]. Children today are able to use the internet in order to browse the web, do homework, play games, follow social media, blog, listen to music, interact via webcam, and venture through cyberspace [54].

Moreover, of what is censored automatically, an even greater proportion of content wanting to be censored but that can be incorrectly censored is educational content. In a study that was done aimed at seeking out programs that either properly or wrong sifted internet content, it was discovered that close to $24 \%$ of educational content was able to be blocked [53]. Today there are various different techniques and programs used to censor the Internet, all of which are ever continuously being improved upon and, 
when taken into consideration, are understood to accurately and reliably work $100 \%$ of the time $[3,21]$. This in turn is why problems can arise when educational content confronts the applied censorship.

A sharp increase in children accessing the World Wide Web is being seen hand in hand as Internet-based technology ever rapidly advances [20]. However, with this comes a number of dangers as well [20]. One study had showed that children who were 8 and under were, to a limited degree, aware of the Internet [14]. Another study had found that $38 \%$ of youth between the ages of $9-19$ had trusted the vast majority of internet content, whilst $49 \%$ had trusted only a portion of what was on the web [36]. Should e-safety training be provided in schools, it still would not be sufficient enough in awakening students to the Internet's many risks [15].

Most families it seems are unaware of the tools that exist that can monitor their children's internet activity. This in essence means that students' internet usage is thus unmonitored as well, and the chance that children are using the web in a safe manner is slim [47].

Within the context of internet-based education, just as there are many benefits, there too are posed dangers - especially for young individuals. In a British study involving 783 teenaged youth, it was shown that when children were scanning the internet for information, they encountered the risks of accidently stumbling upon violent and pornographic content upon entering the resources that came up in their searches [35]. Similarly, in another study done involving 25,142 children between the ages of $9-16$ and from 25 European Union counties, it was determined that children were at clear risk of coming across Internet pornography, cyberbullying, sex chat rooms, establishing relationships with strangers, and other harmful web content [36].

Upon analysis, although the Internet has many a benefit, there also are important risks for students, particularly young students. However, it can be seen that the application of censorship is potentially subjective, and that it can in turn block useful content. In turn, there is a great need to examine the subject of Internet censorship, particularly within the context of education. The main purpose of this study is to reveal how the censoring of websites in Turkey is perceived by teachers. Primary and secondary school teachers are involved in the education of young individuals, seemingly more so than post-secondary instructors. They can address Internet censorship by considering factors such as student characteristics.

\subsection{Research Questions}

The following questions are answered in line with the main purpose of the study:

- What are primary and secondary school teachers' opinions on Internet censorship?
- What are primary and secondary school teachers' opinions on the blocking websites that are able to be used for educational purposes?

- Does Internet censorship affect education quality?

- What are justifications behind primary and secondary school teachers' opinions within the context of Internet censorship?

The teachers' opinions on Internet censorship are analyzed within the context of factors such as whether or not they follow Internet-related developments, whether or not they have previously experienced website censorship, and other factors such as gender, either being a primary or a secondary school teacher, experience, computer skill, and frequency of Internet use.

\section{Materials and Methods}

This study is quantitative in nature and aims to gather the opinions of primary and secondary school teachers alike on the topic of internet censorship. A qualitative research method was preferred in order to reach a broad mass of people as well as examine educators' opinions in deep detail.

\subsection{Participants}

The study was performed during the spring term of the 2014 - 2015 academic year with a voluntary group of 2015 primary and secondary school teachers who were registered with a social networking website providing Turkish-based services. Within this context, primary and secondary school teachers were contacted via the social networking site, where they in turn filled out the survey voluntarily - thus reaching randomly selected teachers in every region of Turkey. The survey was made available to only the teachers with social networking accounts. Each teacher was only able to fill out one survey.

Of the teachers who participated, $29 \%$ were female and $71.1 \%$ were male. Of those, $42.4 \%$ taught in primary school, and $57.6 \%$ taught in secondary school. In terms of teaching experience, $34.5 \%$ of teachers had $1-10$ years, $37 \%$ had $11-20$ years, and $28.5 \%$ had $21+$ years of experience. Furthermore, $2.5 \%$ of teachers possessed limited computer skills, $59.5 \%$ had a medium or functional level of skill, and $38 \%$ were advanced users. In terms of internet use, $31.7 \%$ of teachers used the internet 7 or less hours per week, $23 \%$ used it between $8-14$ hours per week, and $45.1 \%$ used it 15 or more hours per week. $86.7 \%$ of teachers follow Internet-based media. Finally, $71 \%$ of teachers have previously encountered blocked content at least once.

Teachers who participated in the study appear mostly to be male and to be secondary school teachers; however, an equilibrium distribution exists in terms of teaching experience. Moreover, it can be observed that teachers 
have medium-level computer skills and use the Internet 15 hours or more in a week. The majority follows Internet news and media and has encountered blocked websites at least once.

\subsection{Instrument}

The survey method was chosen for this study as surveys enable researchers to define a past or present situation within distinctive conditions without either influencing or altering that given situation in any way whatsoever. Another reason for using the survey method was to enable researchers the ability to obtain detailed data from a large number of people. Furthermore, internet survey method was chosen for this study for a range of reasons [16] including being recognized to be a fast means of collecting data, being low in cost, being able to reach a wider geography and more diverse array of people, being programmable online, and detailed answers being able to be collected from open-ended questions.

In this study, which aims to determine primary and secondary school teachers' opinions on Turkish Internet censorship, “The Survey on Teachers' Opinions Related to Blocking of the Websites" has been used. In developing the survey, first a draft survey was created by making a literature review. Great care was given to ensuring that survey questions highlighted the questions under analysis. Questions were kept from being vague and confusing, using emotional language, and having multiple meanings and interpretations. The draft was presented to experts, and then revised in line with their suggestions and corrections. In the second stage, in order to find out whether survey questions were comprehensible or not, a pilot study was performed on 106 primary and secondary school teachers. The pilot survey was then rearranged and ultimately finalized based on teacher feedback.

The survey has two parts. In the first part are the questions addressing the personal qualities of the teachers. The first section was comprised of seven questions. Each of the qualities in this section was obtained with close-ended questions while the questions pertaining to Internet use frequency and experience were attained with open-ended questions. In the second part, close and open-ended questions aiming to obtain information from the teachers about Internet censorship exist. The second section consisted of six questions, three of which were closed-ended, and three of which were open-ended. In the close ended opinion-oriented questions, positive and negative choices were given in order to determine precisely what direction the participants decided, thus intending to prevent indecision. Closed-ended questions asked whether they (teacher) "supported or didn't support the prevention of accessing certain websites on the Internet", whether they "supported or didn't support the potential use of access prevention within the context of education", and whether "the blocking of certain websites did nor didn't have a negative impact". Open-ended questions sought detailed reasons behind teachers' opinions.

In this study, close and open ended questions together were used as coupling the two yields the best result [49], particularly when all of the answers from the participants cannot be foreseen.

\subsection{Data Analysis}

SPSS (Statistical Package for the Social Sciences) packaged software was used in analyze the data of this study. Frequency, percentage, and arithmetic means as well as the "Chi Square Test" for intergroup comparison were utilized. In addition, open-ended questions obtained through the survey were included in the analysis by being categorized and entered in SPSS environment [49]. Similar or identical categories obtained through open-ended questions were combined and grouped under a main category. Frequency and percentage data were provided in order to interpret the opinions belonging to the aforesaid main category.

\section{Findings}

In this part, the findings pertaining to revealing how website censorship in Turkey is perceived according to teachers' viewpoints and have been considered based on the order set in the purposes section in order to enhance intelligibility. Opinions been examined in terms of personal qualities such as gender and professional branch. Furthermore, more profound findings have been obtained by more deeply analyzing these qualities upon being compared with other qualities.

\subsection{Teachers' Opinions on Internet Censorship}

Table 1. Teachers' opinions on Internet censorship

\begin{tabular}{|c|c|c|c|}
\hline & Group & Number & Percentage \\
\hline \multirow{2}{*}{ All teachers } & Approve & 584 & 59.4 \\
\cline { 2 - 4 } & Disapprove & 1431 & 40.6 \\
\hline
\end{tabular}

In analyzing the opinions on Internet censorship, what's observed is that $59.4 \%$ of the teachers support Internet censorship, while $40 \%$ do not approve of it. Within this context, it can be suggested that the majority teachers support Internet censorship; however there isn't a wide gap between those who approve versus disapprove. The data from the analysis of teacher opinion regarding Internet censorship as based on different qualities are presented Table 2 . 
Table 2. Teachers' Opinions on Internet Censorship Based on Personal Qualities

\begin{tabular}{|c|c|c|c|c|c|c|c|}
\hline & \multirow{2}{*}{ Group } & \multicolumn{2}{|c|}{ Approve } & \multicolumn{2}{|c|}{ Disapprove } & \multirow{2}{*}{$\mathrm{X}^{2}$} & \multirow{2}{*}{$\mathrm{SD}$} \\
\hline & & $\mathrm{N}$ & $\%$ & $\mathrm{~N}$ & $\%$ & & \\
\hline \multirow{2}{*}{ Gender } & Female & 361 & 61.8 & 223 & 38.2 & \multirow{2}{*}{.175} & \multirow{2}{*}{1} \\
\hline & Male & 836 & 58.4 & 595 & 41.6 & & \\
\hline \multirow{2}{*}{ Branch } & Primary & 500 & 58.5 & 355 & 41.5 & \multirow{2}{*}{.497} & \multirow{2}{*}{1} \\
\hline & Secondary & 697 & 60.1 & 463 & 39.9 & & \\
\hline \multirow{3}{*}{ Experience } & $1-10$ Years & 433 & 62.3 & 262 & 37.7 & \multirow{3}{*}{.000} & \multirow{3}{*}{2} \\
\hline & 11-20 Years & 478 & 64.2 & 267 & 35.8 & & \\
\hline & $21+$ Years & 286 & 49.7 & 289 & 50.3 & & \\
\hline \multirow{2}{*}{ Computer Skills } & Medium & 747 & 62.4 & 451 & 37.6 & \multirow{2}{*}{.003} & \multirow{2}{*}{1} \\
\hline & High & 424 & 55.4 & 341 & 44.6 & & \\
\hline \multirow{3}{*}{ Frequency of Internet Use } & 7 hours or less/week & 416 & 65.2 & 222 & 34.8 & \multirow{3}{*}{.000} & \multirow{3}{*}{2} \\
\hline & 8-14 hours/ week & 306 & 65.4 & 162 & 34.6 & & \\
\hline & $15+$ hours / week & 475 & 52.3 & 434 & 42.7 & & \\
\hline \multirow{2}{*}{ Following Internet-based media } & Yes & 1009 & 57.7 & 739 & 42.3 & \multirow{2}{*}{.000} & \multirow{2}{*}{1} \\
\hline & No & 188 & 70.4 & 79 & 29.6 & & \\
\hline \multirow{2}{*}{ Encountered blocked websites } & Yes & 760 & 53.1 & 670 & 46.9 & \multirow{2}{*}{.000} & \multirow{2}{*}{1} \\
\hline & No & 437 & 74.7 & 148 & 25.3 & & \\
\hline
\end{tabular}

In analyzing the opinions according to gender, $61 \%$ of female and $58 \%$ of male teachers supported Internet censorship. These percentages are very close; a difference of opinion between male and female teachers does not appear to exist $\left(\chi^{2}(1, n: 2015)=1.843, p>.05\right)$. Likewise, $58 \%$ of primary and $60 \%$ of secondary school teachers support Internet censorship. Respectively, their opinions are very similar. A meaningful difference between teachers' opinions $\left(\chi^{2}(1, \mathrm{n}: 2015)=.462, \mathrm{p}>.05\right)$ does not appear to exist.

On the other hand, teachers' opinions statistically differ in terms of experience, computer skills, Internet-use frequency, following Internet media, and the encountering of blocked website. In analyzing teacher opinion according experience, $62 \%$ of teachers with $1-10$ years of experience, as well as $64 \%$ with $11-20$ years of support Internet censorship. This is in contrast to $49 \%$ of teachers with 21 plus years' experience $\left(\chi^{2}(1, \mathrm{n}: 2015)\right.$ $=4.500, \mathrm{p}<.05$ ).

Upon analysis of the correlation between opinion and computer skill, only those with a medium to high level of computer skill were considered due to the comparatively tiny number of teachers with limited computer skill. It appears that $62 \%$ of teachers with a medium skill level support Internet censorship more so than the $55 \%$ of teachers with a high skill level $\left(\chi^{2}(1, n: 2015)=9.028\right.$, $\mathrm{p}<.05$ ). Likewise, that $55 \%$ group supports Internet censorship, compared to just $65 \%$ of medium-use and $65 \%$ of low-usage users $\left(\chi^{2}(1, \mathrm{n}: 2015)=35.104, \mathrm{p}<.05\right)$. Of teachers who follow Internet-related media, $57 \%$ support Internet censorship - this, compared with $70 \%$ of non-followers $\left(\chi^{2}(2, \mathrm{n}: 2015)=14.942, \mathrm{p}<.05\right) .53 \%$ of teachers who have encountered website blocking at least once support Internet censorship, compared with $74 \%$ of those who have not encountered any website blocking $\left(\chi^{2}\right.$ $(1, \mathrm{n}: 2015)=79.088, \mathrm{p}<.05)$.

Not only have opinions on Internet censorship been determined, but the reasons behind those opinions have too been studied. Teachers' justifications in support of Internet censorship as well as the number of the teachers expressing that support are presented in Table 3 .

Table 3. Teachers' Justifications for Supporting the Internet Censorship

\begin{tabular}{|c|}
\hline Moral Dimension (218) \\
\hline $\begin{array}{l}\text { Unethical content (83), inappropriate content (69), sexually-explicit } \\
\text { websites }(60) \text {, the automatic-opening of inappropriate websites }(6)\end{array}$ \\
\hline Appropriateness for Children (181) \\
\hline $\begin{array}{c}\text { Inappropriate content for children (121), encourage immoral behaviors } \\
\text { in children (30), websites which evoke psychological problems in } \\
\text { children (24), content which negatively affects children's mental } \\
\text { development (6) }\end{array}$ \\
\hline Negative content (44) \\
\hline $\begin{array}{c}\text { Violence (17), gambling (7), propaganda(6), websites causing } \\
\text { psychological problems in individuals (6), content that harms religious } \\
\text { values (3), websites harmful to social values (3), fright-provoking } \\
\text { websites (2) }\end{array}$ \\
\hline Unawareness (35) \\
\hline $\begin{array}{l}\text { Unawareness of individuals (28), unawareness of children (5), lack of } \\
\text { parental control (2) }\end{array}$ \\
\hline Information pollution (30) \\
\hline $\begin{array}{l}\text { Websites containing information pollution (21), harmful hidden } \\
\text { content(9) }\end{array}$ \\
\hline Other justifications (67) \\
\hline $\begin{array}{l}\text { Harmful content to national values (35), computer-endangering } \\
\text { software (9), negative influence on self-improvement (6), content } \\
\text { impairing social order (5), waste of time (4), illegal content (4), } \\
\text { ill-intentioned users (1), the existence of websites administrated by } \\
\text { ill-intentioned individuals (1), governments need to protect their } \\
\text { citizens from the dangers of the cyber world (1), freedom must be kept } \\
\text { restricted (1) }\end{array}$ \\
\hline
\end{tabular}


Moral justification and inappropriate content for children are the most frequent reasons behind why teachers support Internet censorship. Negative content including violence, gambling, and propaganda websites are also among the mentioned reasoning. Teachers' opinions as to why they do not support Internet censorship are presented in Table 4:

Table 4. Justifications for Why Teachers don't Support Internet Censorship

\section{Freedoms (349)}

Freedom must not be restricted (208), people can control themselves (68), prohibitions attract people (30), families can set up filters for their children (24), personal rights must be respected (10), the decision to block websites is made those who are in power (5), it is not a democratic practice (2), it is an outdated practice (2)

Access to Information (75)

The blocking the websites containing useful content (34), access to information must not be restrained (27), there are ways to access blocked content (14)

It is observed that restriction of freedom and access to information are among the most frequently cited reasons as to why teachers object Internet censorship.

\subsection{Teachers' Opinion on the Blocking of Educational Websites}

Table 5. Teachers' Opinions on the Blocking of Websites Used as Educational Tools

\begin{tabular}{|c|c|c|c|}
\hline & Group & Number & Percentage \\
\hline \multirow{2}{*}{ All teachers } & Approve & 270 & 13,4 \\
\cline { 2 - 4 } & Disapprove & 1745 & 86,6 \\
\hline
\end{tabular}

In analyzing the opinions on the blocking of educational websites, $13.4 \%$ of teachers approve, where as $86.6 \%$ do not approve. Within this context, it can be suggested that teachers overall do not approve of the blocking of sites used for educational purposes. Data analysis of teachers' opinions on this matter as broken down by personal quality is given in Table 6 .

As seen in Table 6 below, teachers appear to overall disapprove of censorship. Simultaneously, gender, experience, computer skills, being either a secondary or primary school teacher, and personally encountering website blocking do not constitute any statistical difference. On the other hand, teachers who use the Internet less frequently appear to support blocking more so than frequent Internet users $\left(\chi^{2}(2, \mathrm{n}: 2015)=9.737\right.$, $\mathrm{p}<.05)$.

Table 6. Teachers' Opinions on Blocking the Websites Used as Educational Tools, by Personal Quality

\begin{tabular}{|c|c|c|c|c|c|c|c|}
\hline & \multirow{2}{*}{ Group } & \multicolumn{2}{|c|}{ Approve } & \multicolumn{2}{|c|}{ Disapprove } & \multirow[t]{2}{*}{$X^{2}$} & \multirow[t]{2}{*}{ SD } \\
\hline & & $\mathrm{N}$ & $\%$ & $\mathrm{~N}$ & $\%$ & & \\
\hline \multirow{2}{*}{ Gender } & Female & 71 & 12.2 & 513 & 87.8 & \multirow{2}{*}{.330} & \multirow{2}{*}{1} \\
\hline & Male & 199 & 13.9 & 1232 & 86.1 & & \\
\hline \multirow{2}{*}{ Branch } & Primary & 101 & 11.8 & 754 & 88.2 & \multirow{2}{*}{.084} & \multirow{2}{*}{1} \\
\hline & Secondary & 169 & 14.6 & 991 & 85.4 & & \\
\hline \multirow{3}{*}{ Experience } & $1-10$ years & 108 & 15.5 & 587 & 84.5 & \multirow{3}{*}{.105} & \multirow{3}{*}{2} \\
\hline & $11-20$ years & 88 & 11.8 & 657 & 88.2 & & \\
\hline & $21+$ years & 74 & 12.9 & 501 & 87.1 & & \\
\hline \multirow{2}{*}{ Computer Skills } & Medium & 145 & 12.1 & 1053 & 87.9 & \multirow{2}{*}{.072} & \multirow{2}{*}{1} \\
\hline & High & 115 & 15.0 & 650 & 85.0 & & \\
\hline \multirow{3}{*}{ Frequency of Internet use } & 7 hours or less a week & 107 & 16.8 & 531 & 83.2 & \multirow{3}{*}{.008} & \multirow{3}{*}{2} \\
\hline & 8-14 hours a week & 60 & 12.8 & 408 & 87.2 & & \\
\hline & $15+$ hours a week & 103 & 11.3 & 806 & 88.7 & & \\
\hline \multirow{2}{*}{ Following Internet-based media } & Yes & 233 & 13.3 & 1515 & 86.7 & \multirow{2}{*}{.889} & \multirow{2}{*}{1} \\
\hline & No & 37 & 13.9 & 230 & 86.1 & & \\
\hline Experiencing website blocking & Yes & 178 & 12.4 & 1252 & 87.6 & .059 & 1 \\
\hline
\end{tabular}


In terms of those who support website blocking, teachers' reasoning and the number of teachers expressing those reasons are given in Table 7:

Table 7. Justifications of the Teachers in Support of Website Blocking

\begin{tabular}{|r|}
\hline All Reasons (9) \\
\hline $\begin{array}{r}\text { The possibility of both unfavorable as well as useful website content (3), for protecting students' moral values (2), children cannot be made } \\
\text { aware of dangerous content (2), blocked websites are already of no value (2), Educational websites may have links to unfavorable websites (1), } \\
\text { designers of the websites are unknown (1) }\end{array}$ \\
\hline
\end{tabular}

Although teachers' justifications include both content-related and moral dimensions, the number of teachers expressing these reasons is relatively low. In terms of objection, teachers' reasoning and the number of teachers expressing such reasons are given in Table 8:

Table 8. Justifications of the Teachers against Website Blocking

\begin{tabular}{|c|}
\hline Restriction on knowledge (331) \\
\hline $\begin{array}{c}\text { Restriction on knowledge (131), educational content must be accessed (88), impeding access to knowledge (62), the Internet is useful (22), it } \\
\text { contributes to education (22), it negatively affects education (4), the quantity of blocked sites limit children's ability to research (2) }\end{array}$ \\
\hline Access opportunity (67) \\
\hline Freedom must not be restricted (56), websites are blocked without sufficient examination (7), only unfavorable websites must be blocked (4) \\
\hline Other reasons (9) \\
\hline $\begin{array}{c}\text { Technology in education must be utilized (4), websites are sometimes shut down for political reasons (3), it must be left to children to know } \\
\text { right from wrong (2) }\end{array}$ \\
\hline
\end{tabular}

Teachers against website blocking appear to mainly be against the restriction of knowledge and access to that knowledge.

Table 9. Teachers' Opinions Website Censorship and the Negative Impact on Education

\begin{tabular}{|c|c|c|c|}
\hline & Group & Number & Percentage \\
\hline \multirow{2}{*}{ All teachers } & Yes & 796 & 39,5 \\
\cline { 2 - 4 } & No & 1219 & 60,5 \\
\hline
\end{tabular}

Upon looking at Table 10, 39.5\% of teachers think website censorship does impact education. However, $60.5 \%$ do not website censorship negatively impacts education. It can be suggested that majority of the teachers think that the blocking of certain websites does negatively impact education. Further analysis of the presented statistics as broken down by various qualities, is presented in Table 10:

Table 10. Teachers' Opinions Website Blocking and the Negative Impact on Education, by Personal Quality

\begin{tabular}{|c|c|c|c|c|c|c|c|}
\hline & \multirow{2}{*}{ Group } & \multicolumn{2}{|c|}{ Yes } & \multicolumn{2}{|c|}{ No } & \multirow{2}{*}{$\mathrm{X}^{2}$} & \multirow{2}{*}{ SD } \\
\hline & & $\mathrm{N}$ & $\%$ & $\mathrm{~N}$ & $\%$ & & \\
\hline \multirow{2}{*}{ Gender } & Female & 227 & 38.9 & 357 & 61.1 & \multirow{2}{*}{.748} & \multirow{2}{*}{1} \\
\hline & Male & 569 & 39.8 & 862 & 60.2 & & \\
\hline \multirow{2}{*}{ Branch } & Primary School & 348 & 40.7 & 507 & 59.3 & \multirow{2}{*}{.369} & \multirow{2}{*}{1} \\
\hline & Secondary School & 448 & 38.6 & 712 & 61.4 & & \\
\hline \multirow{3}{*}{ Experience } & $1-10$ years & 267 & 38.4 & 428 & 61.6 & \multirow{3}{*}{.000} & \multirow{3}{*}{2} \\
\hline & $11-20$ years & 260 & 34.9 & 485 & 65.1 & & \\
\hline & $21+$ years & 269 & 46.8 & 306 & 53.2 & & \\
\hline \multirow{2}{*}{ Computer skills } & Medium & 478 & 39.9 & 720 & 60.1 & \multirow{2}{*}{.799} & \multirow{2}{*}{1} \\
\hline & High & 300 & 39.2 & 465 & 60.8 & & \\
\hline \multirow{3}{*}{ Internet use frequency } & 7 hours or less a week & 242 & 37.9 & 396 & 62.1 & \multirow{3}{*}{.001} & \multirow{3}{*}{2} \\
\hline & 8-14 hours a week & 158 & 33.8 & 310 & 66.2 & & \\
\hline & $15+$ hours a week & 396 & 43.6 & 513 & 56.4 & & \\
\hline \multirow{2}{*}{ Following Internet-based media } & Yes & 707 & 40.4 & 1041 & 59.6 & \multirow{2}{*}{.032} & \multirow{2}{*}{1} \\
\hline & No & 89 & 33.3 & 178 & 66.7 & & \\
\hline \multirow{2}{*}{ Experience with website blocking } & Yes & 629 & 44.0 & 801 & 56.0 & \multirow{2}{*}{.000} & \multirow{2}{*}{1} \\
\hline & No & 167 & 28.5 & 418 & 71.5 & & \\
\hline
\end{tabular}


According to Table 10, it appears that the most teachers feel that there isn't a negative impact on education. Gender, computer skill, and being either a primary or secondary school teacher do not appear to make any difference. On the other hand, teachers with $21+$ years of experience tend to think that it does $\left(\chi^{2}(2, n: 2015)\right.$ $=19.700, \mathrm{p}<.05)$. Likewise, the group with frequent Internet use strongly feels that will be negatively impacted $\left(\chi^{2}(2, \mathrm{n}: 2015)=13.391, \mathrm{p}<.05\right)$. The teachers who follow Internet media $\left(\chi^{2}(2, \mathrm{n}: 2015)=4.903, \mathrm{p}<.05\right)$ and who have experienced website blocking at least once $\left(\chi^{2}(2, \mathrm{n}\right.$ : 2015) $=40.765, \mathrm{p}<.05)$ also think that it does affect education negatively, this more so than those who do not follow Internet media, respectively. Justifications for the teachers' opinions based on the above are given in Table11:

Table 11. Justifications for the teachers' opinions

\begin{tabular}{|c|}
\hline All reasons (7) \\
\hline $\begin{array}{c}\text { People always find a way to access blocked content (4), Prohibitions } \\
\text { arouse interest (3) }\end{array}$ \\
\hline
\end{tabular}

With regards to the negative impact on education, few people expressed their opinion. Justifications thus are given in Table 12:

Table 12. Justifications for Opinions on Website Blocking and Negative Education Impact

\section{Websites that aren't currently blocked are sufficient (94)}

Websites that aren't currently blocked are sufficient (30), the websites which are blocked are of no value (30), blocking negative contents does not negatively affect education (18), the blocking of negative websites accelerates access to correct information (8), individuals can access unobjectionable information (5), it isn't/will not become a problem if the correct Internet sources are chosen (3)

Other reasons (43)

Different information sources can be used (38), age restriction is beneficial (5)

It can be observed that teachers by and large argue that the blocking of certain websites doesn't and won't negatively affect education, due to the fact that blocked websites are (seen as being) of little value. They think that unfavorable websites have already been blocked, thus positively affects education. In analyzing the justifications, unblocked websites appear to be sufficient.

\section{Discussion}

In concluding the study, it was found that $59.4 \%$ of the teachers believe that Internet censorship must be applied. Of that, no statistical difference was found between primary school teachers $(58.5 \%)$ and middle school teachers $(60.1 \%)$. Our findings correlate with the findings of an American study in which $47 \%$ of the participants claimed that only certain of information should appear on the Internet [17]. In terms of those who support internet censorship worldwide, in one Chinese study done, while $80 \%$ of participants expressed being in support of internet censorship [34], 74\% of Australians [59], 83\% of South Koreans, $77 \%$ of Nigerians, and $72 \%$ of Mexicans [9] were against internet censorship. However, in another study done involving participants from Hong Kong, India, Indonesia, Japan, South Korea, Malaysia, Pakistan, Singapore, Taiwan, Thailand, and Vietnam, over two out of every three people were in support of Internet censorship, keeping in mind that that approximately $90 \%$ felt the internet to be a basic human [55]. Thus, it too is worth noting Turkey's relatively high statistic, with $56.4 \%$ of teachers being in favor of internet censorship. In a 2010 Greek study involving 55 people with advanced education [32], $47 \%$ of participants stated that the Internet must be censored completely, while $31 \%$ stated it should be censored under certain conditions. Furthermore, the percentage of teachers who believe in the necessity of Internet censorship is much higher than that of a study conducted by [48] involving 138 university students. In yet another study done by [46] involving 299 university students, it was found that $28 \%$ of students supported Internet censorship. This finding may imply that primary and secondary school teachers in Turkey believe in Internet control more so than university students do. It is thought that this stems from the difference in the students' age group and context of education.

When little or no statistical relationship in terms of opinion, gender, and area exists, it is believed that more experienced teachers who have a high level of computer skill, who frequently use the Internet, who follow Internet-based media, who have experienced internet censorship first hand see less of a need for internet censorship when compared with their counterparts. It can be noted that teachers with more professional experience as well as those who spent a great deal of time on the Internet, were more familiar with it, and used it frequently were most against Internet censorship. Comparatively, the relatively similar results of Shen \& Tsui's [55] study revealed that the need not to restrict freedom was the single most important behind teachers being against the employment of Internet censorship and, on the subject confronting harmful content, they felt that individuals can control themselves, that people are drawn to what's forbidden, that people's personal rights must be respected, and that families can use internet filters if felt to be necessary. Sexually explicit content, inappropriate content for children, and unfavorable content like gambling and violence are the most prominently cited reasons in which why teachers think positively about the Internet censorship. Studies produced both by Livingstone \& Harper [35] as well as Livingstone, Haddon, Gorzing \& Olafsson [36] justify teachers due to the fact that teenagers are likely to wrongly encounter negative content such as violence and pornography, as well as that children are not able to control themselves and that content which both pollutes knowledge and poses a threat to a country's national values exists. These findings are parallel to the findings of a 2007 Chinese study [34] in which more than 
$80 \%$ of participants stated that pornographic and violent content must be censored. Similarly, a study [55] revealed that over two out of every three users expressed that Internet censorship is necessary. On the other hand, teachers objecting to Internet censorship cited restriction on both freedom as well as Internet access as reasons. This is parallel with the 26-country BBC study [9] in which $79 \%$ of participants regarded the Internet as being a fundamental right.

The majority of both primary school teachers $(88.2 \%)$ and secondary school teachers $(85.4 \%)$ do not approve the blocking of education-intentioned websites. On the other hand, teachers who use the Internet less frequently support the Internet censorship more so than those whose frequency of usage is either medium or high. Teachers object to the blocking of websites used as educational tools on the grounds that censorship limits information and restricts the opportunity to access information that can be used for the purposes of education. The finding of a study done by Richardson, Resnick, Hansen, Derry \& Rideout [53] revealed that the fact that censorship can potentially block educational content supports its negative impact within the context of education. The number one reason teachers support placing restrictions accessing of websites that can be used within education is that harmful content exists on the Internet. Harmful Internet content thus feeds into concerns by educators [36].

$59.3 \%$ of primary and $61.4 \%$ of secondary school teachers believe that the blocking of certain websites will affect education negatively. However, teachers with extensive professional experience of 21 years or more, coupled with high Internet use frequency appear to believe that Internet censorship will affect education even more negatively. Likewise, those who follow the Internet media and have experienced website blocking also believe that education will be more negatively impacted. One important finding thus that experienced teachers as well as teachers who more frequently use and are more familiar with the Internet is of the opinion that censorship impacts education negatively. According to some educators, reasons such as the Internet being able to be used as a fountain of knowledge and that currently unblocked websites are sufficiently beneficial, in turn avoiding the negative impact that restricting websites can have. On the other hand, some teachers feel that there is a negative impact on students in that restrictions arouse interest. Research conducted by Hobbs and Roberts [28] shows this to be true, showing that encountered blocked content heightens the interest in both it and in finding a way to access it.

\section{REFERENCES}

[1] Aaronson, S. A. (2016). At the Intersection of Cross-Border Information Flows and Human Rights: TPP as a Case Study.
The George Washington University, Institute for International Economic Policy, Washington.

[2] Aceto, G., Botta, A., Pescapé, A., Awan, M.F., Ahmad, T. \& Qaisar, S.B. (2016). Analyzing internet censorship in Pakistan. In IEEE 2nd International Forum on Research and Technologies for Society and Industry Leveraging a Better Tomorrow (IEEE RTSI), Bologna, Italy, September 2016.

[3] Aceto, G., Montieri, A. \& Pescape, A. (2016). Internet censorship in Italy: A first look at $3 \mathrm{G} / 4 \mathrm{G}$ networks. In Cryptology and Network Security 15th International Conference, CANS Milan, Italy, November 14-16, 2016 (pp. 737-742).

[4] Aceto, G., \& Pescape, A. (2015). Internet censorship detection: A survey. Computer Networks, 83, 381-421.

[5] Aktay, S. (2008). The Effect of the Internet on the Quality of Education. The International Journal of Learning, 15(4), 81-88.

[6] Anderson, D. (2012). Splinternet behind the great firewall of China. ACM Queue 10(11), 1-10.

[7] Aryan, S., Aryan, H. \& Halderman, J. A. (2013). Internet censorship in Iran: A first look. USENIX Workshop on Free and Open Communications on the Internet (FOCI), aug 2013.

[8] Barrron, A. E. \& Ivers, K. S. (1998). The internet and instruction: Activities and ideas. Colorado: Libraries Unlimited, Inc.

[9] BBC World Service (2010). Four in five regard Internet access as a fundamental right: Global poll. Retrieved from http://www.globescan.com/newsarchives/bbc2010_internet/

[10] Bidgoli, H. (2004). The internet encyclopedia. New Jersey: John Wiley \& Sons.

[11] Boyle, A. (1996). Censorship ranks as top internet issue. Retrieved from

http://www.cc.gatech.edu/gvu/user_surveys/press/msnbc/46 431.html

[12] Callanan, C. \& Jerman-Blazic, B. (2016). User awareness and tolerance of privacy abuse on mobile Internet: An exploratory study. Telematics and Informatics, 33(1), 109128.

[13] Chaabane, A., Chen, T., Cunche, M., Cristofaro, E. D., Friedman, A. \& Kaafar, M. A. (2014). Censorship in the wild: Analyzing internet filtering in Syria. In Internet Measurement Conference 2014 (pp. 285-298).

[14] Chaudron, C. (2015). Young children (0-8) and digital technology: A qualitative exploratory study across seven countries. Luxembourg: European Union: Joint Research Centre.

[15] Cranmer, S., Selwyn, N., \& Potter, J. (2009). Exploring primary pupils' experiences and understandings of 'e-safety'. Education and Information Technologies, 14(2), 127-142.

[16] Czaja, R. \& Blair, J. (2005). Designing surveys: A guide to decisions and procedures. London: Sage Publications, Inc.

[17] Depken, C. A. (2006). Who supports internet censorship? First Monday, 11 (9). Retrieved from http://firstmonday.org/ojs/index.php/fm/article/view/1390/1 
308

[18] Dixon, L., Ristenpart, T. \& Shrimpton, T. (2016). Network traffic obfuscation and automated internet censorship. arXiv preprint arXiv:1605.04044.

[19] Du, Y. R. (2016). Same events, different stories internet censorship in the Arab spring seen from China. Journalism \& Mass Communication Quarterly, 1-19.

[20] Edwards, S., Nolan, A., Henderson, M., Mantilla, A., Plowman, L., \& Skouteris, H. (2016). Young children's everyday concepts of the internet: A platform for cyber safety education in the early years. British Journal of Educational Technology. DOI: 10.1111/bjet.12529

[21] Elahi, T., Swanson, C. M., \& Goldberg, I. (2015). Slipping past the cordon: A systematization of internet censorship resistance. Centre for Applied Cryptographic Research (CACR), University of Waterloo, Tech. Rep, 10

[22] Engelliweb.com (2016). Erisime engellenen siteler [The websites which were blocked]. Retrieved from http://engelliweb.com/istatistikler/

[23] Epstein, Z. (2014). The most important thing you'll see today: Internet censorship world map. Retrieved from http://bgr.com/2014/02/20/internet-censorship-world-map/

[24] Gupta, V. (2003). Internet and web design. New Delhi: Dreamtech Press.

[25] Hamade, S. N. (2008). Internet filtering and censorship. In Fifth International Conference on Information Technology: New Generations, Las Vegas, Nevada April 7-9.

[26] Hamilton, J. (2005). Internet. United States: Abdo Publishing Company.

[27] Internetworldstats.com (2017a). Internet growth statistics. Retrieved from http://www.internetworldstats.com/emarketing.htm

[28] Internetworldstats.com (2017b). World Internet Users and 2017 Population Stats. Retrieved from http://www.internetworldstats.com/emarketing.htm

[29] Hobbs, W. \& Roberts, M. E. (2016). How sudden censorship can increase access toinformation. Retrieved from $\mathrm{http} / /$ www.margaretroberts.net/wp-content/uploads/2016/0 8/selfiecensorship.pdf

[30] Karasar, N. (2003). Bilimsel Arastirma Yontemi [Scientific Research Method]. Ankara: Nobel Publishing.

[31] Khattak, S., Javed, M., Khayam, S. A., Uzmi, S. A. \& Paxson, V. (2014). A look at the consequences of internet censorship through an isp lens. In IMC '14 Proceedings of the 2014 Conference on Internet Measurement Conference, 2014 (pp. 271-284).

[32] Koumartzis, N. (2010). Greek internet regulation survey. Retrieved from http://webobserver.net/2010/11/07/greek-internet-regulatio n-survey-2010/

[33] LeMay, R. (2005). Blog censorship gains support. Retrieved from https://www.cnet.com/news/blog-censorship-gains-support/

[34] Liang, G. (2007). Surveying internet usage and its impact in seven chinese cities. Retrieved from

http://research.policyarchive.org/16013.pdf

[35] Livingstone, S. \& Helsper, E. (2009). Balancing opportunities and risks in teenagers' use of the internet: The role of online skills and internet self-efficacy. New Media \& Society, 11(8), 1-25.

[36] Livingstone, S., Haddon, L., Gorzig, A. \& Olafsson, K. (2010). Risks and safety on the internet. LSE, London: EU Kids Online.

[37] Lu, T., Zhao, J., Zhao, L., Li, Y. \& Han, W. (2016). An analysis of internet censorship circumvention techniques. International Journal of Security and Its Applications, 10(5), 63-72.

[38] Magsi, A. H., Shaikh, A. W., Kehar, A., Talpur, M. S. H. \& Depar, M. H. (2016). Measuring the efficiency of web censorship in Pakistan. Asian Journal of Engineering, Sciences \& Technology (Special issue), 62-64.

[39] Nabi, Z. (2013). The anatomy of web censorship in Pakistan. USENIX Workshop on Free and Open Communications on the Internet.

[40] Nabi, Z. (2014). Censorship is futile. First Monday 19(11).

[41] Nawaz, S., Ali, R., Batool, S. \& Alaudeen, Z. (2015). Use of Internet among Youth and its Effect on Library Attendance. Pakistan Journal of Information Management \& Libraries (PJIM\&L), 16 (2015), 29-37.

[42] Netcraft (2017a). September 2017 web server survey. Retrieved from https://news.netcraft.com/archives/2017/09/11/september-2 017-web-server-survey.html

[43] Netcraft (2017b). October 2017 web server survey. Retrieved from https://news.netcraft.com/archives/2017/10/26/october-201 7-web-server-survey-13.html

[44] OpenNet Initiative (2016). Research. Retrieved from https://opennet.net/research

[45] Oliver, F., Darer, A. \& Wright, J. (2016). Poisoning the well: Exploring the great firewall's poisoned dns responses. In WPES '16 Proceedings of the 2016 ACM on Workshop on Privacy in the Electronic Society 2016 (pp. 95-98).

[46] Ozcinar, H. \& Tanyeri, T. (2016). The relationship between undergraduates' view on internet censorship, and their media literacy level. Usak Universitesi Sosyal Bilimler Dergisi, 9(2), 165-188.

[47] Ozgur, H. (2016). The relationship between Internet parenting styles and Internet usage of children and adolescents. Computers in Human Behavior, 60, 411-424.

[48] Ozkan, H. \& Arikan, A. (2009). Internet censorship in Turkey: University students' opinions. World Journal on Educational Technology, 46-56.

[49] Pallant, J. (2003). SPSS survival manual. Buckingham: Open University Press.

[50] Pandey, A. (2016). Attitude towards Importance of Internet in Modern Education. Global Journal for Research Analysis, $5(1), 251-252$

[51] Pfoeffer, P. (2002). Web usability and children: current 
research and implications for information professionals. Orana, 38(2), 11-13.

[52] Reese, J. (1999). Internet Books for Educators, Parents, and Students. Colorado: Libraries Unlimited, Inc.

[53] Richardson, C. R., Resnick, P. J., Hansen, D. L., Derry, H. A. \& Rideout, V.J. (2002). Does Pornography-Blocking Software Block Access to Health Information on the Internet?, The Journal of the American Medical Association 288(22), 2887-2894.

[54] Scott, J. (2016). Children and the internet: An exploration of Year 5 pupils' online experiences and perceptions of risk. Journal of Huddersfield student research, 2(1).

[55] Shen, F. \& Tsui, L. (2016). Public opinion toward internet freedom in Asia: A survey of internet users from 11 Jurisdictions. Berkman Center Research Publication, 2016 (8).

[56] Tkacz, E., \& Kapczynski, A. (2009). Internet-Technical development and applications (Vol. 64). Springer Science \& Business Media.
[57] U.S. Department of Education. 2013. Digest of Education Statistics 2012 (NCES 2014-015). National Center for Education Statistics, Institute of Education Sciences, U.S. Department of Education. Washington, DC.

[58] Varol, O. (2016). Spatiotemporal analysis of censored content on Twitter. In WebSci '16 Proceedings of the 8th ACM Conference on Web Science 2016 (pp. 372-373).

[59] Whirlpool.net.au. (2007). Australian broadband survey 2007. Retrieved from http://whirlpool.net.au/survey/2007/

[60] Wright, J. (2016). Regional variation in Chinese internet filtering. Information, Communication \& Society 17(1), $121-141$

[61] Zittrain, J. L. \& Palfrey, J. G. (2007). Access denied: The practice and policy of global internet filtering. Oxford Internet Institute, Research Report No. 14.

[62] Zuchora-Walske, C. (2010). Internet censorship: Protecting citizens or trampling freedom? USA: Lerner Publishing Group. 